\title{
Behaviour and distribution of heavy metals at the boundary of "water-bottom sediments" in mouth zones of rivers
}

\author{
Anna Mikhailenko*, Irina Dotsenko, Asya Ovsepyan, and Alina Zimovets \\ Institute of Earth Sciences, Southern Federal University, 344090 Rostov-on-Don, Zorge str. 40, \\ Russia
}

\begin{abstract}
The aquatic elementary landscapes of the Don and Northern Dvina Rivers mouth zones as arenas of mass transfer of heavy metals (HM) are studied. The results of long-term comprehensive studies of the authors, which included sampling of water and the upper layer of bottom sediments in order to determine the content of mercury, copper, methane, hydrogen sulfide, as well as $\mathrm{pH}$ and $\mathrm{Eh}$ values, are presented. According to the type of prevailing geochemical conditions and the level of anthropogenic impact, natural, manmade and natural-anthropogenic aquatic elementary landscapes are distinguished. The bottom water layers in both rivers were characterized by positive Eh values, but it should be noted that they were generally relatively low for surface watercourses. According to the values of the redox potential and the hydrogen index, the methane content and the total hydrogen sulfide, the presence of the following conditions is proved - oxygen, gley, hydrogen sulfide, oxygen-gley and gley-hydrogen sulfide. At the water - sediment interface, in most cases, there was a decrease in $\mathrm{pH}$ values by the first tenths of the values, while Eh usually decreased quite sharply, often to negative values. In terms of methane content, the bottom sediments of the aquatic elementary landscapes of the Don and Northern Dvina rivers were similar, while the concentration of total hydrogen sulfide was higher in the Don. It is shown that in the mouth zone of the Don and Northern Dvina rivers, in areas subject to constant organic pollution and eutrophication, there is an increase in the total content of mercury and copper in the bottom sediments. Higher concentrations of gross mercury will generally be found in natural and anthropogenic landscapes dominated by hydrogen sulfide and gley-hydrogen sulfide environments. The important role of microparticles of the polydisperse medium of bottom sediments in the deposition of copper and mercury is revealed.
\end{abstract}

\section{Introduction}

The study of aquatic landscapes of rivers mouth zones as an arena for the mass transfer of heavy metals (HM) is a topical area of geochemical research. The theoretical foundations of landscape science were laid in works [1-4, etc.]. By analogy with the elementary landscape identified by B. B. Polynov on land, we propose to distinguish aquatic elementary landscapes in the surface hydrosphere. As the smallest natural-territorial

\footnotetext{
* Corresponding author: avmihailenko@,sfedu.ru
} 
complex, it includes water, biota, suspended matter and bottom sediments [5]. Bottom sediments play an important role in the processes taking place in elementary aquatic landscapes. The significance of this component in the distribution and behavior of HM is largely determined by the lithological composition, sedimentation rates, content and composition of organic matter and gases, morphology, as well as the dynamics of interaction between all components. In this work, the mouth zones of the Don and Northern Dvina rivers are considered by us as a set of elementary aquatic landscapes. The considered water areas are characterized by significant differences in climatic, hydrological, hydrochemical and biological conditions, the nature, structure and degree of anthropogenic pressure on the described aquatic ecosystems. In this regard, from a scientific and applied point of view, it was important to study the physicochemical characteristics of water and bottom sediments, their lithological composition, levels of content and distribution of reduced gases, mercury and copper in the mouth areas of the River Don and Northern Dvina River.

\section{Materials and methods}

The work is based on the results of long-term comprehensive studies of the authors, which included sampling of water and the upper layer of bottom sediments in order to determine the content of mercury, copper, methane, hydrogen sulfide, as well as $\mathrm{pH}$, Eh values. The analyses were carried out according to the methods presented in the publications [6-11]. Generalization, analysis, and comparison of the distribution and behavior of physical and chemical characteristics, methane, hydrogen sulfide, and HM content in aquatic elementary landscapes were performed.

\section{Results and discussion}

According to the type of prevailing geochemical conditions and the level of anthropogenic impact in the study areas, the aquatic elementary landscapes were identified, each of which was characterized by certain quantitative characteristics [5]. Natural, man-made, and natural-anthropogenic aquatic elementary landscapes were identified. According to the values of the redox potential and the hydrogen index, the methane content and the total hydrogen sulfide, the presence of the following conditions is proved: oxygen, gley, hydrogen sulfide, oxygen-gley, and gley-hydrogen sulfide (Fig. 1, 2). 


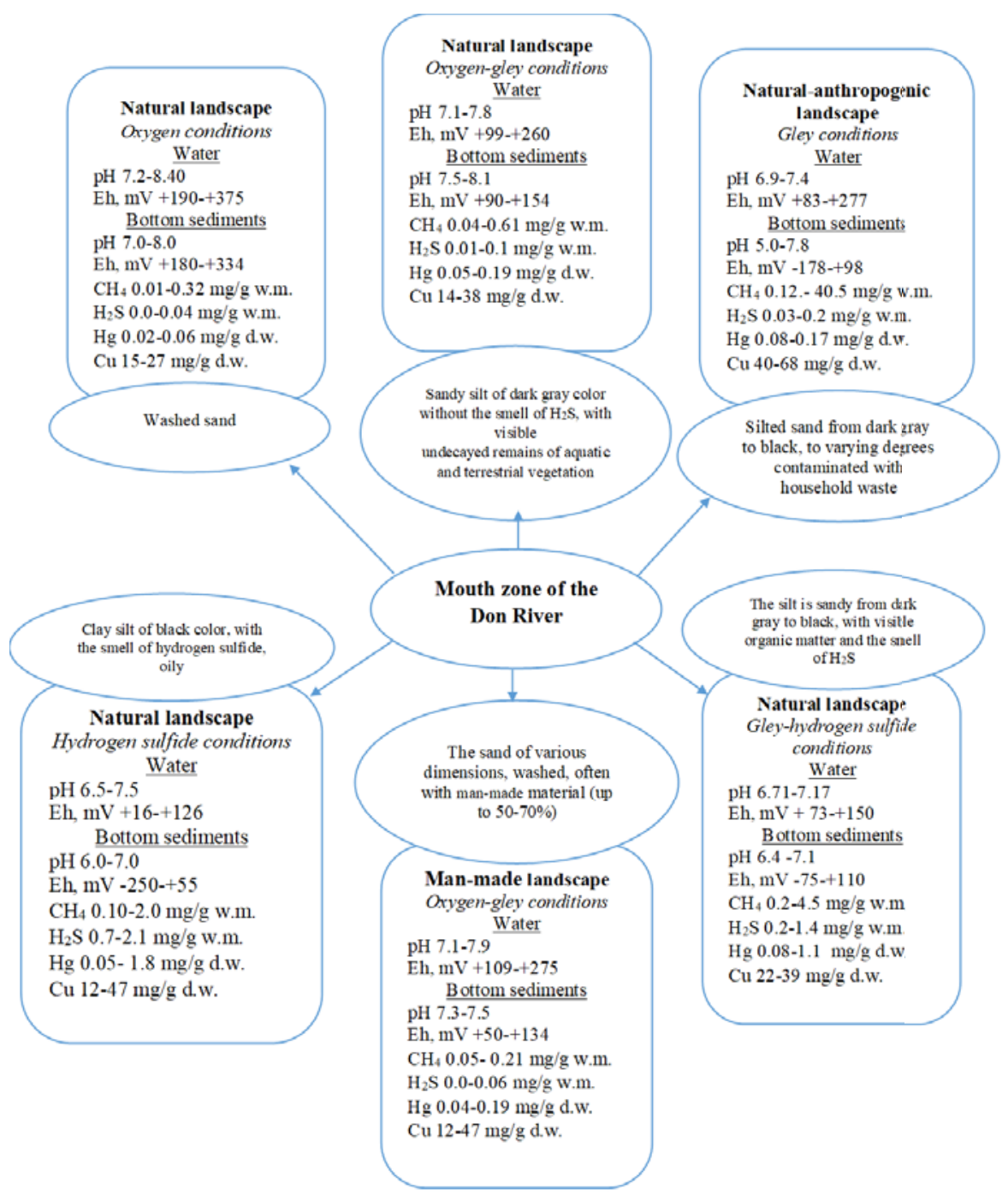

Fig. 1. Modification of $\mathrm{pH}$, Eh, and the content of reduced gases and heavy metals in the aquatic elementary landscapes of the River Don mouth zone [5, with additions]

The general trend for the aquatic elementary landscapes was to decrease the values of Eh and, less contrastingly, $\mathrm{pH}$ in the bottom layers of water and the upper layer of bottom sediments in the direction of oxygen $\rightarrow$ gley $\rightarrow$ hydrogen sulfide conditions (Fig. 1, 2). The bottom layers of water in both rivers were characterized by positive values of Eh, but it should be noted that they, as a rule, were relatively low for surface watercourses. At the water - sediment interface, in most cases, there was a decrease in $\mathrm{pH}$ values by the first tenths of the values, while the Eh value usually decreased quite sharply, often to negative values. It was found that for the Don River, the $\mathrm{pH}$ and Eh values of the bottom water horizon and the upper layer of bottom sediments were even slightly higher than for the Northern Dvina. As noted earlier in $[7,8,11]$, the methane content of the bottom sediments of the aquatic elementary landscapes of the Don and Northern Dvina rivers was similar, while the concentration of total hydrogen sulfide was higher in the Don. A higher content of both methane and hydrogen sulfide was found in natural-anthropogenic and man-made landscapes with a predominant gley-hydrogen sulfide environment (Fig. 1, 2). The highest 
concentrations of total hydrogen sulfide were observed in natural and anthropogenic landscapes with a hydrogen sulfide environment. The mercury content in bottom sediments increases in a similar way, while copper behaves relatively indifferently. Both metals show an increase in the content in natural landscapes with an increase in the proportion of fine silt fraction and an increase in anthropogenic impact. On the basis of theoretical and experimental studies of the authors, it is proved that the hydrogen sulfide environment contributes to a slowdown in the rate of mass transfer of mercury from bottom sediments to water, which is associated with the formation of hydrosulfides and mercury sulfides, as well as isomorphic capture by hydrotrolyte.

At low values of Eh and, accordingly, the oxygen content, free hydrogen sulfide can play a shielding role, converting mercury into its sulfide. In a gley and gley-hydrogen sulfide environment, increased mercury emissions in the form of elemental and methylmercury are possible, since bacteria methanogens, and to some extent sulfate reducers, contribute to their formation. When the environment changes from hydrogen sulfide to oxygen-hydrogen sulfide and even oxygen as a result of the oxidation of free hydrogen sulfide to elemental sulfur, the sorption of the last emitting mercury and the accumulation of bottom sediments in the upper layer is possible $[6,12,13]$. However, the deposition of mercury may not occur if the deposition rate is not high and the elemental sulfur has time to oxidize to sulfate ions. Mercury, together with methane, can diffuse to the surface of bottom sediments. Another way is also possible, namely, convective transport, when the methane formed, when the pressure in the bottom sediments is exceeded, is able to break through them and be released in the form of gas bubbles. In the Don River mouth zone, this is favored by wind effected phenomena, and in the Northern Dvina by tidal phenomena, which create prerequisites for the release of elemental mercury and its mobile organic gaseous forms when precipitation is stirred up [7]. The process of mass transfer of heavy metals in the water - bottom sediment system is influenced by a certain chemical factor. It is particularly pronounced in the areas of aquatic anthropogenic sedimentogenesis. In the zones of anthropogenic impact in some places due to acidification of water, it is possible to dissolve $\mathrm{ZnS}, \mathrm{CdS}, \mathrm{PbS}$, as well as hydroxides of $\mathrm{Zn}, \mathrm{Cd}$ and $\mathrm{Cu}$ in the areas of water alkalinization. However, the presence of fulvic acids may play an important role in mass transfer processes [5, 14]. Our studies performed for the Northern Dvina River confirm this [8]. The content of dissolved mercury showed a close correlation with the concentration of fulvic acids, which suggested that it was mainly found in the dissolved form of migration in the composition of fulvate complexes. We add that the presence of Fe, $\mathrm{Cu}, \mathrm{Mn}$, and $\mathrm{Al}$ accelerates the methylation of $\mathrm{Hg}_{2}+$ with fulvic acid, and this process is also active in the dark at $\mathrm{pH}$ values of 4.0-4.5 [15]. Thus, in the mouth zones of the Don and Northern Dvina rivers, in areas subject to constant organic pollution and eutrophication, the probability of formation in the presence of high concentrations of HM, for example, copper, the most toxic form of mercury - methylmercury - increases significantly. 


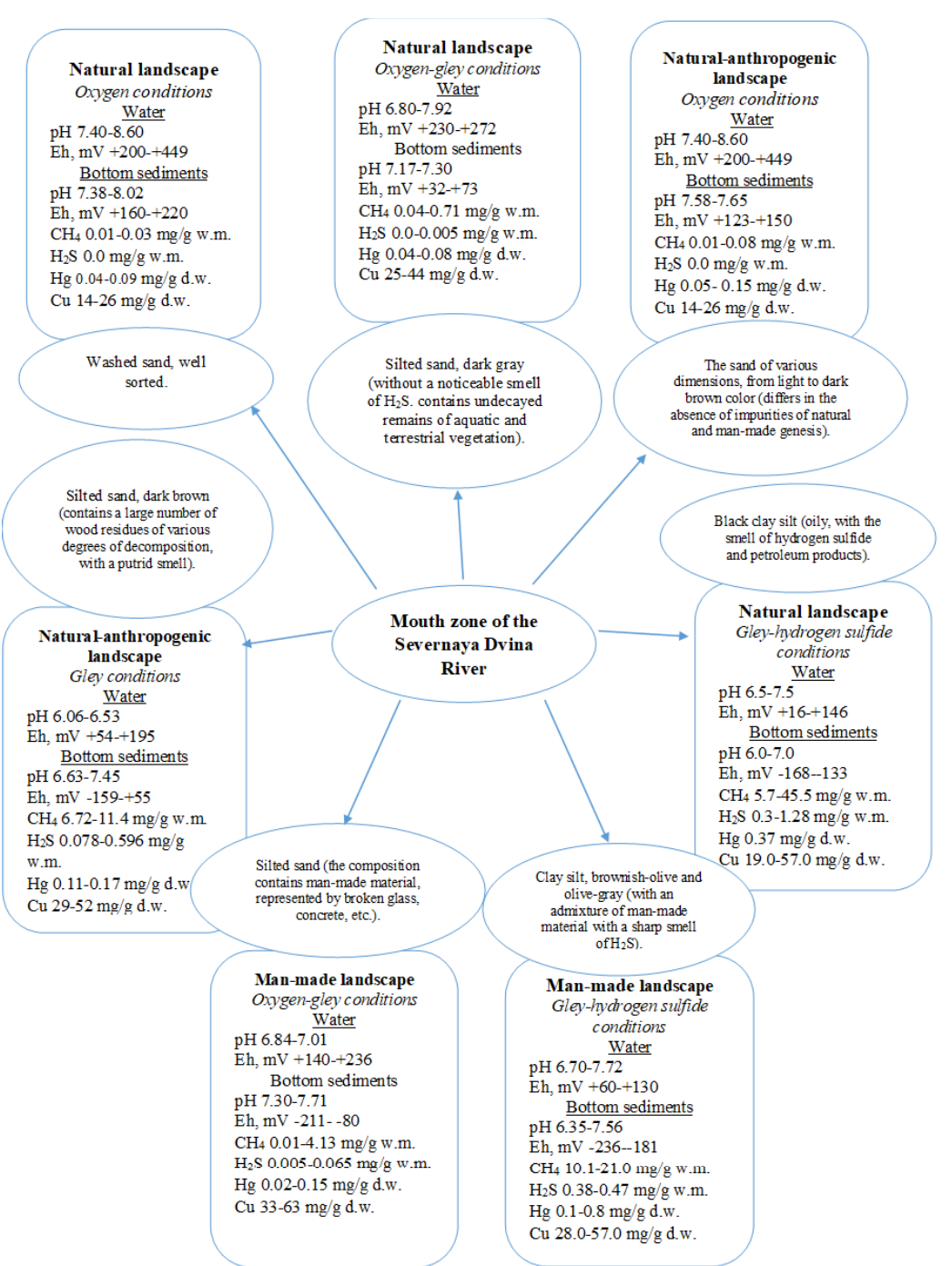

Fig. 2. Modification of $\mathrm{pH}$, Eh, and the content of reduced gases and heavy metals in the aquatic elementary landscapes of the river Northern Dvina mouth zone (compiled according to [5-11])

Let us consider the approaches and principles of zoning of bottom sediments according to the ability to emit heavy metals. In the uppermost layer of bottom sediments, aerobic, anaerobic and anaerobic-aerobic conditions can be formed, which depend on the physicochemical, hydrological conditions, the content and type of organic matter, the bacterial community, the lithological composition of bottom sediments and the degree of anthropogenic impact. Based on the prevailing conditions and processes occurring in the mouth zone of the Northern Dvina River, an approach to spatial zoning of the water area based on the prevailing forms of mercury in the upper horizon of bottom sediments has been theoretically justified and experimentally confirmed [11], as well as implemented, which, taking into account the specifics of the Don River mouth zone, has been successfully adapted here. It is shown that the methylation processes are most developed in those elementary aquatic landscapes where the bottom sediments are mainly represented by the pelitic fraction and the anaerobic gley environment dominates. In landscapes with a hydrogen sulfide environment, where the processes of sulfate reduction are active, running 
in parallel with the processes of methylation and suppressing them, part of the formed mercury is bound and then deposited in the deeper layers of bottom sediments in the form of its sulfides, as well as in the sorbed form on iron sulfides, pelitic particles and humic acids. The highest rates of methylmercury formation, with its close gross contents in bottom sediments, should be expected in aerobic and aerobic-anaerobic conditions (landscapes with oxygen, oxygen-gley) and anaerobic (gley) environments. At the same time, higher concentrations of gross mercury will be characterized, as a rule, by natural and anthropogenic landscapes, where hydrogen sulfide and gley-hydrogen sulfide conditions prevail.

\section{CONCLUSION}

According to the type of prevailing geochemical conditions and the level of anthropogenic impact, the aquatic elementary landscapes were identified, each of which was characterized by certain quantitative characteristics. Natural, man-made and natural-anthropogenic aquatic elementary landscapes were identified. According to the values of $\mathrm{pH}$ and Eh, methane content and total hydrogen sulfide, the presence of the following conditions is proved: oxygen, gley, hydrogen sulfide, oxygen-gley, and gley-hydrogen sulfide. At the boundary between the water-bottom sediments of the Don and Northern Dvina Rivers, a distinct change in $\mathrm{pH}$ and Eh values is observed. A common feature of the aquatic elementary landscapes is the tendency to decrease the values of Eh and, less contrastingly, $\mathrm{pH}$ in the bottom layers of water and the upper layer of bottom sediments in the direction of oxygen $\rightarrow$ gley $\rightarrow$ hydrogen sulfide environment. The mercury content in bottom sediments increases in a similar way, while copper behaves relatively indifferently. Both metals show an increase in the content in natural landscapes with an increase in the proportion of fine silt fraction and an increase in anthropogenic impact. It is shown that the hydrogen sulfide environment contributes to a slowdown in the rate of mass transfer of mercury from bottom sediments to water, which is associated with the formation of hydrosulfides and mercury sulfides. Microglobulas of hydrotroylite and other iron sulfides are more prone to isomorphic capture of mercury.

This work was supported by the President of the Russian Federation, grant no. 1862.2020.5. Interpretation of the results was supported by the Russian Science Foundation (project no. 19-0550097).

\section{References}

1. B. B. Polynov, Questions of geography, 33. 30-44 (1953)

2. F. N. Milkov, Physical geography: the study of landscape and geographical zonality (Voronezh, 1986)

3. A. I. Perelman, N. S. Kasimov, Geochemistry of the landscape (Astreya-2000, Moscow, 1999)

4. M. A. Glazovskaya, Geochemical bases of typology and methods of research of natural landscapes (Oikumena, Smolensk, 2002) (in Russian)

5. Yu. A. Fedorov, A. V. Mikhailenko, I. V. Dotsenko, Conf. Proc. of Geochem. of Landsc. and Geogr.of Soils (to the 100th anniversary of M. A. Glazovskaya, 332-334 (2012) (in Russian)

6. Yu. A. Fedorov, I. V. Dotsenko, A. V. Mikhailenko, Conf. Proceed. of 11-th Int. Multidiscipl. Scient. GeoConf. \&EXPO Modern Manag. of Mine Producing, Geol. and Env. Prot., SGEM 2011, Bulgaria. III, 717-722 (2011) 
7. Yu. A. Fedorov, A.E. Ovsepyan, Izv. Vuz.. Sev.-Kavk. Reg. Nat. Sc. No. 2, pp. 82-89 (2006) (in Russian)

8. D. N. Gar'kusha, Yu. A. Fedorov, Oceanology, 54(2), 160-169 (2014)

9. Yu. A. Fedorov, A.A. Zimovets, A.E. Ovsepyan, I.V. Dotsenko, Izv. Vuz. Sev.-Kavk. Reg. Nat. Sc., 2, 86-89 (2011) (in Russian)

10. Yu. A. Fedorov, A. E. Ovsepyan, V. B. Korobov, I. V. Dotsenko, Rus. Meteor. and Hydr., 35(9), 611-618. (2010)

11. Yu. A. Fedorov, A. E. Ovsepyan, V. B. Korobov, Rus. Meteor. and Hydr., 35(4), 289294 (2010)

12. Yu. A. Fedorov, A. V. Mikhailenko, I.V. Dotsenko, Water Resources, 46(Suppl. 2), S59-S64 (2019)

13. Yu. A. Fedorov, I. V. Dotsenko, A. V. Mikhailenko, Conf. Proceed. of 14-th Int. Multidiscipl. Scient. GeoConf. \&EXPO Modern Manag. of Mine Producing, Geol. and Env. Prot., SGEM 2014, Bulgaria. II, 423-430 (2014)

14. P. N. Linnik, B. I. Nabivanets, Forms of metal migration in fresh surface water (L.: Gidrometeoizdat, 1986). (in Russian)

15. Y.H. Lee, H. Hultberg, I. Anderson, Water, Air and Solid Pollut. 25(4), 391-400 (1985) 